\title{
Immunogenicity of Recombinant DNA Human Insulin
}

\author{
S. E. Fineberg, J. A. Galloway, N. S. Fineberg, M.J. Rathbun and S. Hufferd \\ Department of Medicine, Indiana University School of Medicine, and Lilly Laboratory for Clinical Research, Indianapolis, Indiana, USA
}

\begin{abstract}
Summary. We postulated that human insulin of recombinant DNA origin would be a poor immunogen and might prove to be less immunogenic than purified pork insulin. Results are reported for 100 diabetic subjects not previously treated with insulin. Individuals completed the first 12 months of a clinical trial of human insulin of recombinant DNA origin. These patients are contrasted with 121 similar individuals who are taking part in a trial of purified pork insulin. Prior to therapy, species-specific binding of ${ }^{125} \mathrm{I}$ human insulin and pork insulins and insulin bound to antibody were undetectable in all individuals. In patients treated with human insulin of recombinant DNA origin, binding of ${ }^{125} \mathrm{I}$ human insulin increased to $10 \pm 1.2 \%$ at 12 months versus increases in binding of ${ }^{125} \mathrm{I}$ pork insulin in pork insulin-treated patients to $12.6 \pm 1.4 \%$ (NS). Mean percentages of species-specific binding tended to reach a plateau in the human insulin-treated group but continued to increase in the pork insulin group $(p<0.001)$. Median bound values were nil throughout in patients treated with human in-
\end{abstract}

sulin, but increased to $52 \mathrm{mU} / 1$ in the pork insulin group with significantly less bound insulin seen in the former group at all visits $(p<0.001)$. The percentage of individuals who remained antibody free at 12 months, as indicated by bound insulin, was $56 \%$ in the human insulin-treated patients and $40 \%$ in the patients treated with pork insulin $(p<0.01)$. In 11 out of 55 individuals who initially developed detectable insulin antibodies while being treated with human insulin, bound insulin levels later became undectable compared with three out of 77 individuals in the pork insulin-treatment group $(p<0.005)$. Human insulin of recombinant DNA origin is less immunogenic than purified pork insulin. Level of antibodies in patients treated with human insulin of recombinant DNA origin reached a plateau after 6 months and antibody levels often tended subsequently to decrease below detection limits.

Key words: Human insulin, immunogenicity of insulin, insulin antibodies.
Virtually all patients treated with conventionally purified insulins develop circulating insulin antibodies [1]. Such antibodies develop less often and in lower concentrations in individuals treated with highly purified porcine insulins than in individuals treated with less purified insulins $[2,3]$. Apart from trace amounts of proinsulin and other pancreatic peptides which may remain after extraction and purification of animal insulins, human insulin differs from porcine insulin only with regard to the terminal amino acid of the $B$ chain [4]. In the absence of antibody formation, clinical and biological effects of these insulins would be predicted to be equivalent since this site is not involved in receptor binding [5]. However, it is conceivable that human insulin of recombinant DNA origin (rDNA) might differ in immunogenicity from pancreatic porcine insulin.

We hypothesized that human insulin (rDNA), when injected in a repository form (as NPH), would prove to be a poor immunogen and would be less immunogenic than purified porcine insulins.

\section{Materials and Methods}

One hundred diverse diabetic subjects, who had not been previously treated with insulin, are participating in a multicentre, unblinded, clinical trial of human insulin of recombinant DNA origin. Insulin was begun when clinically indicated by the patients' own physicians and adjusted according to individual needs. These patients were compared with 121 similar diabetic patients who participated in a noncontemporaneous, multicentre, double-blind clinical trial of purified porcine insulins. Only two investigators participated in both trials. Patients treated with purified porcine insulin were enrolled first. Informed consent was obtained before participation and all studies conformed to principles outlined by the Declaration of Helsinki. Patients with detectable antibody levels before therapy were excluded. Patients were evaluated for the presence of insulin antibodies at 2-month intervals.

Human insulin used for these studies was formulated from bulk crystals in an NPH repository form containing salmon protamine $(0.36-0.40 \mathrm{mg} / 100$ units). Crystal lots contained $0.6-1.2 \%$ of desamido insulin. Pork insulin was administered as NPH insulin containing salmon protamine $(0.40 \mathrm{mg} / 100$ units $)$ or insulin zinc suspension (Lente) insulin. Of the patients treated with purified porcine insulin, 59 were treated with NPH and 62 with Lente. Crystals from which these insulins were formulated contained $0.8 \%$ desamido insulin. In 
Table 1. Patient characteristics

\begin{tabular}{lll}
\hline & \multicolumn{2}{l}{ Treatment groups } \\
\cline { 2 - 3 } & $\begin{array}{l}\text { Human insulin } \\
\text { (rDNA) } \\
(n=100)\end{array}$ & $\begin{array}{l}\text { Purified pork } \\
\text { insulin } \\
(n=121)\end{array}$ \\
\hline Age (years) & $\begin{array}{l}46.1 \pm 2.0 \\
(5-83)\end{array}$ & $\begin{array}{l}44.7 \pm 1.8 \\
(6-76)\end{array}$ \\
Sex & $58 \mathrm{M}, 42 \mathrm{~F}$ & $67 \mathrm{M}, 54 \mathrm{~F}$ \\
Ideal body weight (\%) [16] & $\begin{array}{l}119.1 \pm 3.0 \\
(76-273)\end{array}$ & $113.1 \pm 2.7$ \\
& $(60-219)$ \\
Duration of diabetes (years) & $5.8 \pm 0.6$ & $4.7 \pm 0.5$ \\
& $(0-27)$ & $(0-21)$ \\
Non-insulin-secreting/ & $51 / 48$ & $51 / 51$ \\
insulin secreting & & \\
Divided/single dose & & \\
\hline
\end{tabular}

Results are given as mean \pm SEM with ranges in parentheses.

a See Methods section, ${ }^{b}$. patients who were treated with human insulin (rDNA) were treated with a divided dose regimen more often than individuals treated with pork insulin, $p<0.001$

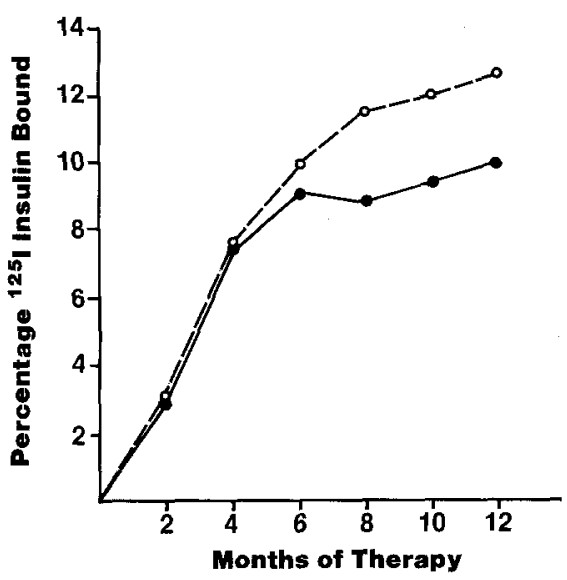

Fig. 1. Development of percentage of species-specific binding of human ${ }^{125} \mathrm{I}$ insulin in subjects treated with human insulin (rDNA) and pork ${ }^{125} 1$ insulin for patients treated with purified porcine insulin. 0.0 : purified porcine insulin-treated patients, $-\longrightarrow$ : human insulin (rDNA)-treated patients. Data were compared by two-way, repeated measures analysis of variance

our studies, Lente and NPH insulins of animal origin were found to be immunogenically equivalent [6]. Purified pork insulin was manufactured from pancreases supplied by slaughterhouses specializing in pork products and contained no detectable beef insulin $(<0.05 \%)$ and $2.25 \pm 0.37 \mathrm{ppm}$ of pork proinsulin. Human insulin (rDNA) and purified porcine insulin used for these studies have been fully characterized and compared previously [7].

Insulin antibody levels were measured using fasting serum obtained $12-24 \mathrm{~h}$ after the patient's last insulin. All measurements for a particular individual were performed in the same assay. Species-specific insulin binding to immunoglobulins (for human, species-specific binding of human insulin, or pork insulin, species-specific binding of pork insulin) was assessed using acid-charcoal extracted sera [8]. ${ }^{125} \mathbf{I}$ pork and human (rDNA) insulins used for all antibody measurements were iodinated by a lactoperoxidase method. Insulins monoiodinated on the fourteenth amino acid of the A chain were selected and purified by high pressure liquid chromatography, specific activities ranged between $340-360 \mu \mathrm{Ci} / \mu \mathrm{g}$ [9]. Final 1:10 dilutions of extracted sera $(0.120 \mathrm{ml}$ of a $1: 4$ dilution of serum) were incubated in a volume of $0.3 \mathrm{ml}$ at $37{ }^{\circ} \mathrm{C}$ for $2 \mathrm{~h}$ along with $1 \mu \mathrm{U} /$ tube of ${ }^{125} \mathrm{I}$ insulin. Antibody bound insulin was precipitated by polyethylene glycol (PEG) [10]. Interassay control serum binding (from the same normal individuals) was $7.4 \pm 1.6 \%$ (mean $\pm \mathrm{SD}$ ) for pork ${ }^{125} \mathrm{I}$ insulin, $6.5 \pm 1.5 \%$ for human, and $10.3 \pm 2 \%$ for beef insulin. Control serum binding was determined in each assay. Results are reported as percentage bound/total (sample) - percentage bound/total (control). Differences in protein concentrations, incubation conditions and other modifications account for the high percentage of binding in the control serum. We have recently compared our method with that of other investigators using PEG precipitation and found highly comparable results throughout the range of samples studied including the ability to distinguish very low binding in treated patients from control sera [6]. Significant binding was judged to be present when binding exceeded two times the maximum coefficient of variation seen for control binding, that is $4 \%$. Total and free insulin were measured using non-extracted aliquots of sera and PEG precipitation of anti-insulin antibody [11]. Total insulin was determined by freeing all insulin bound antibody by $\mathrm{HCl}$, precipitating antibodies by $\mathrm{PEG}$, and measuring supernatant insulin concentrations. Free insulin was measured by precipitating antibodies and bound insulin by PEG and measuring supernatant insulin concentrations. Supernatant insulin concentrations were measured using Heding's method [12]. Recovery was determined in each assay. This averaged $87.3 \pm 4.7 \%$ for free and $75.4 \pm 3.0 \%$ for total insulin. Circulating insulin bound to antibodies was the difference between total and free insulin concentrations. Bound insulin concentrations were significant, if after correction for recovery, total insulin - 2SD was greater than free insulin $+2 \mathrm{SD}$.

C-peptide concentrations were measured by methods published previously [13]. Fasting and 2-h stimulated C-peptide levels (after $240 \mathrm{ml}$ Sustacal, Mead Johnson, Evansville, Indiana, USA) were obtained before the studies began. To classify patients as secretion deficient and insulin secreting, use was made of the lower limits for this assay for normal and fasting and stimulated levels, of 0.33 and $1.17 \mathrm{pmol} / \mathrm{ml}$, respectively. Algorithms used have been published previously [6] and are summarized as follows: if fasting C-peptide levels were $<0.33 \mathrm{pmol} / \mathrm{ml}$ or stimulated levels were $<1.17 \mathrm{pmol} / \mathrm{ml}$, then $=$ secretion deficient or non-insulin secreting. If fasting levels were $\geqslant 1.17 \mathrm{pmol} / \mathrm{ml}$ and $/$ or stimulated levels were $\geqslant 1.17 \mathrm{pmol} / \mathrm{ml}$ and at least 1.5 times the baseline value, then $=$ insulin secreting. Data were unavailable for one patient in the human insulin (rDNA) and 12 patients in the pork insulin-treatment groups. Seven patients treated with pork insulin could not be classified by these algorithms.

Only patients with complete species-specific binding data and a history of continuous insulin therapy for one year were analyzed. Data were analyzed using standard statistical packages available through the Indiana University Computing Network. Group comparisons were performed using the Chi-square test for discrete data with Fisher's exact test for two by two tables [14]. Repeated measures over time were compared between groups by two way analysis of variance. Groups were treated as an independent factor and multiple values as a repeated measure [15]. Comparisons of non-parametric data utilized the Wilcoxon rank sum test [14].

\section{Results}

\section{Patient Characteristics}

Patients in both treatment groups were comparable (Table 1). These individuals encompassed a broad range of age, duration of disease and percentage ideal body weight. When classified by initial insulin secretory status (based on fasting and stimulated C-peptide concentrations before therapy) [6], equivalent proportions of the individuals from both groups were deficient in insu- 
lin secretion or had preserved secretion; however, seven individuals could not be classified in the purified porcine insulin group. A significantly greater porportion of individuals treated with human insulin of recombinant DNA origin received divided doses than individuals treated with purified porcine insulin.

\section{Comparison of Insulin Antibody Development Between Human Insulin (rDNA) and Purified Porcine Insulin- Treated Patients}

Figure 1 shows species-specific binding of human and pork ${ }^{125} \mathrm{I}$ insulin. Insulin antibody concentrations increased significantly over the course of treatment as indicated by species-specific binding of human and porcine insulins (both $p<0.001$ ). Significant differences from baseline were seen for both treatment groups by 4 months. At the 12 month visit, differences between mean percentages of species-specific binding for human insulin (rDNA) and purified porcine insulin-treated patients were not significant $(10 \pm 1.2 \%$ versus $12.6 \pm 1.5 \%$ respectively). However, after 6 months, the

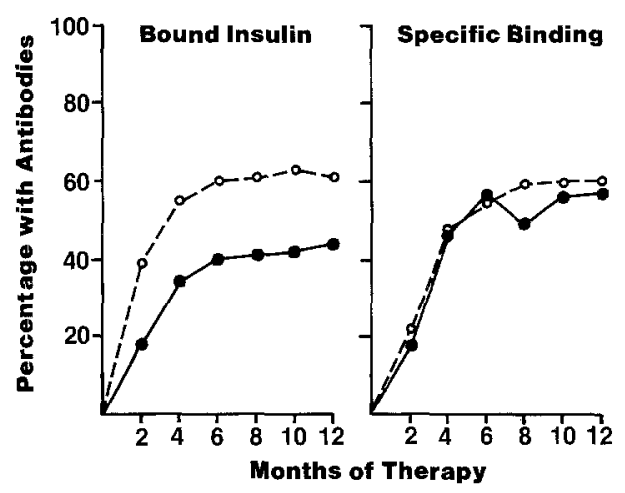

Fig. 2. Percentage of individuals who developed antibodies at each visit as indicated by measurement of bound insulin and species-specific binding. The percentage of individuals who developed significant levels of bound insulin were less at each visit in the human insulin (rDNA) treatment group $(p<0.001)$. Percentages of individuals who developed species-specific binding $>4 \%$ were similar for both groups. Data were compared using Fisher's exact test for two by two tables and adjustments were made for repeated measures.

$\mathrm{O}-\mathrm{O}$ : purified porcine-insulin treated; $\longrightarrow$ : human insulin (rDNA)-treated patient mean percentage of specific binding in patients treated with human insulin (rDNA) tended to reach a plateau, whereas the percentages continued to rise in the purified porcine insulin group. The interaction term between these curves indicated that this divergence was significant $(p<0.001)$.

The mean percentages of individuals who developed detectable antibodies at each visit are shown in Figure 2. The percentage of patients treated with human insulin (rDNA) who developed detectable levels of bound insulin was significantly less than for patients treated with purified porcine insulin (all $p<0.001$ ). Only $44 \%$ of the human insulin (rDNA) group had detectable bound insulin at 12 months versus $60 \%$ of the purified porcine insulin group. The percentage of individuals who had insulin antibodies detectable by species-specific binding were not significantly different between the groups. In patients who had undetectable bound insulin levels but a significant percentage of species-specific binding, all but one had percentages of binding of $<10 \%$ at 12 months.

Species-specific and bound insulin were highly correlated when analyzed by rank analysis $(r=0.85$ and $p<0.01$ at 12 months for all data). However, bound insulin data were not normally distributed and were therefore analyzed by the Wilcoxon rank sum test [13]. Median bound insulin levels and ranges are given in Table 2. Over $50 \%$ of the human insulin-treated patients had no elevation in bound insulin levels, whereas median values in the purified porcine insulin-treated group rose to $52 \mathrm{mU} / 1$ at 12 months. The medians for the two groups were significantly different throughout $(p<0.005)$.

\section{Loss of Antibody Detectability in Human Insulin (rDNA) and Purified Porcine Insulin-Treated Patients}

Table 3 compares purified porcine and human insulin (rDNA)-treated patients with regard to individuals who lost detectability of bound insulin or species-specific binding insulin after initial development of insulin antibodies. Eleven out of 55 individuals treated with human insulin lost detectability of bound insulin compared with three out of 77 patients treated with purified por-

Table 2. Development of bound insulin in patients treated with human insulin (rDNA) and purified pork insulin

\begin{tabular}{|c|c|c|c|c|c|c|}
\hline Treatment Group & \multicolumn{6}{|c|}{ Time (months) } \\
\hline Human insulin (rDNA) (mU/l) & $\begin{array}{l}0 \\
(0-377)\end{array}$ & $\begin{array}{l}0 \\
(0-525)\end{array}$ & $\begin{array}{l}0 \\
(0-757)\end{array}$ & $\begin{array}{l}0 \\
(0-465)\end{array}$ & $\begin{array}{l}0 \\
(0-512)\end{array}$ & $\begin{array}{l}0 \\
(0-591)\end{array}$ \\
\hline Purified pork insulin (mU/l) & $\begin{array}{l}0 \\
(0-467)\end{array}$ & $\begin{array}{l}24 \\
(0-982)\end{array}$ & $\begin{array}{l}35 \\
(0-1061)\end{array}$ & $\begin{array}{l}38 \\
(0-3246)\end{array}$ & $\begin{array}{l}46 \\
(0-1319)\end{array}$ & $\begin{array}{l}52 \\
(0-3941)\end{array}$ \\
\hline$p^{\text {a }}$ & 0.001 & 0.001 & 0.005 & 0.001 & 0.001 & 0.001 \\
\hline
\end{tabular}

Median concentrations are given with ranges in parenthesis.

a Probability is given that the groups differed. Data were analyzed by the Wilcoxon rank sum test [14] 
Table 3. Comparison of loss of detectability of insulin antibodies in the two groups studied

\begin{tabular}{|c|c|c|c|}
\hline & $\begin{array}{l}\text { Human } \\
\text { insulin } \\
\text { (rDNA) }\end{array}$ & $\begin{array}{l}\text { Purified } \\
\text { porcine } \\
\text { insulin }\end{array}$ & $\mathrm{p}^{\mathrm{a}}$ \\
\hline \multicolumn{4}{|l|}{ Bound Insulin } \\
\hline $\begin{array}{l}\text { Loss of detectability prior } \\
\text { to the } 12 \text {-month visit }\end{array}$ & 11 & 3 & 0.005 \\
\hline$>0$ at 12 months & 44 & 74 & \\
\hline \multicolumn{4}{|l|}{ Specific Binding } \\
\hline $\begin{array}{l}\text { Loss of specific binding } \\
\text { prior to the } 12 \text { month visit }\end{array}$ & 13 & 7 & 0.07 \\
\hline$>4 \%$ at 12 months & 57 & 73 & \\
\hline
\end{tabular}

${ }^{a}$ The probability is given that loss of detectability differed between the treatment groups

cine insulin $(p<0.005)$. Similar losses of detectability of specifically bound insulin were also seen but differences between the groups were not significant.

\section{Discussion}

Use of purified pork insulins has decreased but not eliminated insulin antibody formation in man. Potential advantages of an antibody-free state include freedom from lipoatrophy and allergic phenomena, decreased insulin dose, predictability of insulin absorption, preservation of endogenous secretion of insulin, and possible avoidance of the generation of anti-idiotypic antibodies [17]. Older studies, however, using recrystallized pancreatic human insulin cast some doubt upon the possibility that injected homologous insulin can be made non-immunogenic [18]. Human insulin of recombinant DNA origin is the first product of DNA technology which has become widely availabe for clinical trials and eventual use in patients. It is chemically identical to endogenous insulin and is free of pancreatic contaminants $[4,7]$. Preliminary short-term studies suggested that this insulin did provoke formation of IgE antibodies but was free of problems associated with clinical allergy [19]. Furthermore, it was of immunological benefit in patients whose treatment was changed from animal insulins $[20,21]$.

The development of the insulin antibodies depends not only on genetic factors but also on insulin formulations and control of self-recognition by the recipient [22, 23]. Patients participating in these studies would be expected to have a broad genetic background since both insulin-secreting patients with non-insulin-dependent diabetes, as well as insulin-deficient patients with insulin-dependent diabetes were included. We have not as yet typed these individuals with regard to immune reponse genes (HLA types associated with immune responsiveness) which may aid further in selecting individuals who would be expected to have a greater or lesser immune response to injected insulins [5].
Diabetic patients treated from the beginning with depot insulins of homologous or closely similar structure developed significant insulin antibody levels by 4 months after the initiation of therapy. However, qualitative binding of iodinated insulins as indicated by species-specific binding was found to reach a plateau after the 6 month visit in the human insulin (rDNA) group, whereas binding tended to increase further in the purified porcine insulin group. In keeping with these observations quantitative estimates of binding as reflected by antibody bound (PEG precipitable) insulin remained low in both groups but were significantly less at all visits in patients treated with human insulin (rDNA). These low levels of antibody were many-fold lower than those detected by a recently developed IgG specific solid phase assay and by our methods in patients treated with animal insulins of mixed origin $[6,24]$. Furthermore, the relatively weaker immunogenicity of human insulin (rDNA) versus purified porcine insulin probably results in the frequent loss of insulin antibodies observed in human insulin (rDNA)-treated patients (Table 3). Clearly the single amino acid difference between human and pork insulin contributes to significant differences in immunogenicity.

The relationship of serum antibody titres to the occurrence of dermal reactions to insulin is not known. One human insulin (rDNA)-treated patient developed two transient episodes of immediate hypersensitivity after 18 months of therapy versus two porcine insulintreated individuals who developed dermal allergic reactions during the first year.

The formation of insulin antibodies in human insulin (rDNA)-treated diabetic patients cannot be due to differences in structure from endogenous insulin, nor can it be attributed to insulin aggregation. In previous studies, it was shown that the presence of significant endogenous insulin secretion prior to therapy was associated with suppressed immune recognition of human insulin (rDNA) [22].

Immunogenicity of human insulin (rDNA) may also be attributed in part to the route of administration, deamidation of insulin, the repository formulation of the insulins used, or the inherent immunogenicity of the body's own proteins, including even insulin [25]. Fiftysix percent of individuals treated with human insulin (rDNA) did not develop antibodies as detected by bound insulin levels versus $40 \%$ in the purified porcine insulin group. In contrast, the vast majority of individuals treated with mixed beef/pork insulins for 6 months develop insulin antibodies. This insulin contains 35 parts per million proinsulin and $70 \%$ beef insulin [6]. The fundamental question of whether human insulin (rDNA) can be administered in a non-immunogenic way remains for future investigations.

Acknowledgements. We wish to express our gratitude to the following: the laboratory of Dr. A. H. Rubenstein, Department of Medicine, University of Chicago, Pritzker School of Medicine; the following physi- 
cians and their patients who participated in this study: Dr. B. Boshell, Birmingham, AL; Dr. J.Davidson, Dallas, TX; Dr. H.L. Dobson, Houston, TX; Dr. A. L. Drash, Pittsburgh, PA; Dr. G. Duncan, Philadelphia, PA; Dr. D. D. Etzweiler, Minneapolis, MN; Dr. R. A.Guthrie, Wichita, KS; Dr. A. Krosnick, Trenton, NJ; Dr. R.L. Nielson, Seattle, WA; Dr. R. L. Poucher, Santa Ana, CA; Dr. O.P. Schumacher, Cleveland, OH; Dr. I. L.Spratt, San Bernadino, CA; Dr. J.I.Starr, Worcester, MA; Dr. T.Steinberg, Orange, CA; Dr. J.W.Stephens, Portland, OR; Dr. F.W. Whitehouse, Detroit, MI. The assistance of the following personnel of Eli Lilly is greatly appreciated: Dr. B. H. Frank, for assistance with preparation of ${ }^{125} \mathrm{I}$ insulins; T.Spradlin for study design; J. Inguilli-Fattic, D. Allemenos, and G.Cokinos for assistance with preliminary data handling and sorting. Preparation of this manuscript was made possible by the secretarial assistance of M.J. Smith. Supported by Eli Lilly and Company $9842 \mathrm{D}$ and the Diabetes Research and Training Center, Indiana University School of Medicine, P608 M20542

\section{References}

1. Klaff LJ, Vinik AI, Berelowitz M, Jackson WPU (1978) Circulating antibodies in diabetics treated with conventional and purified insulins. S Afr Med J 54: 149-153

2. Reeves WG, Kelley V (1980) An immunochemical method for the quantitation of insulin antibodies. J Immunol Meth 34: 329-338

3. Falholt K (1982) Determination of insulin specific IgE in serum of diabetic patients by solid phase radioimmunoassay. Diabetologia 22: 254-257

4. Chance RE, Kroeff EP, Hoffman JA, Frank BH (1981) Chemical physical and biologic properties of biosynthetic human insulin. Diabetes Care 4: 147-154

5. Kahn RC, Rosenthal AS (1979) Immunologic reactions to insulin: Insulin allergy, insulin resistance and the autoimmune insulin syndrome. Diabetes Care 2: 283-295

6. Fineberg SE, Galloway JA, Fineberg NS, Goldman J (1983) Effects of species of origin, purification levels, and formulation upon immunogenicity. Diabetes 32: 592-599

7. Johnson IS (1982) Authenticity and purity of human insulin (recombinant DNA). Diabetes Care 5 (Suppl 2): 4-12

8. Dixon K (1974) Measurement of antibodies to insulin in serum. Clin Chem 20: 1275-1281

9. Frank BH (1980) HPLC preparation of high specific activity 125-I labels of insulin, proinsulin and other polypeptide hormones. Diabetes 29 (Suppl 2): 106A

10. Goldman J, Baldwin D, Pugh W, Rubenstein AH (1978) Equilibrium binding assay and kinetic characterization of insulin antibodies. Diabetes 27:653-660

11. Nakagawa $S$, Nakayama $H$, Sasaki $T$, Yoshino $K$, Yu Y, Shinozaki K, Aoki S, Mashimo K (1973) A simple method for the determination of serum free insulin levels in insulin treated diabetic patients. Diabetes 22: 590-600

12. Heding LG (1971) Determination of total serum insulin in insulintreated diabetic patients. Diabetologia 8: 260-66
13. Kuzuya H, Blix PM, Horowitz DL, Steiner DF (1977) Determination of face and total insulin and C-peptide in insulin-treated patients. Diabetes 26: 22-29

14. Dixon WJ, Massey FJ (1969) Introduction to statistical analysis. McGraw Hill, New York

15. Winer BJ (1971) Statistical prinicples in experimental design, 2nd edition. McGraw Hill, New York, pp 261-283

16. Anonymous (1959) New weight standards for men and women. Statistical Bulletin Metropolitan Life Insurance Co 40 (NovDec): $1-4$

17. Shechter Y, Maron R, Elias D, Cohen IR (1982) Autoantibodies to insulin receptor spontaneously develop as anti-idiotypes in mice immunized with insulin. Science 216: 542-545

18. Deckert T, Andersen OO, Grundahl E, Kerp L (1972) Isoimmunization of man by recrystallized human insulin. Diabetologia 8 : 358-361

19. Fireman P, Fineberg SE, Galloway JA (1982) Development of IgE antibodies to human insulin (recombinant DNA), porcine and bovine insulins in diabetic subjects. Diabetes Care 5 (Suppl 2): $119-125$

20. Fineberg SE, Galloway JA, Fineberg NS, Rathbun MJ (1982) Immunologic improvement resulting from the transfer of animal-insulin treated diabetic subjects to human insulin (recombinant DNA). Diabetes Care 5 (Suppl 2): 107-113

21. Maneschi F, Fineberg SE, Kohner EM (1982) Successful treatment of immune mediated insulin resistance by human insulin (recombinant DNA). Diabetes Care 5 (Suppl 2): 175-179

22. Fineberg SE, Fineberg NS, Galloway JA, Rathbun MJ, Hufferd S (1982) The impact of insulin secretory status upon the immune response to insulin in man. In: Programme of the Endocrine Society, 64th Annual Meeting, San Francisco, California. Endocrine Society, Bethesda, Maryland, p 158

23. Weigle WO (1981) Self-nonself recognition of T and B lymphocytes and their roles in autoimmune phenomena. Arthritis Rheum 24: 1044-1053

24. Hamilton RG, Rendell M, Adkinson NF (1980) Serological analyses of human $\operatorname{IgG}$ and IgE anti-insulin antibodies by solid phase radioimmunoassays. J Lab Clin Med 96: 1022-1036

25. Galloway JA, Root MA, Bergstrom R, Spradlin CT, Howey DC, Fineberg SE, Jackson RL (1982) Clinical pharmacologic studies with human insulin (recombinant DNA). Diabetes Care 5 (Suppl 2): 13-22

Received: 31 December 1982

and in revised form: 22 July 1983

Dr. S. Edwin Fineberg

Indiana University School of Medicine

Regenstrief Health Center, Room 603

1001 West 10th Street

Indianapolis, IN 46202

USA 